\title{
Incarcerated Amyand's Hernia with Destructive Appendicitis Complicated with Myocardial Infarction. A Case Report and Review of the Literature
}

\author{
Dimitar Hadzhiev ${ }^{1 *}$, Dzhevdet Chakarov ${ }^{1}$, Evgeniy Moshekov ${ }^{1}$, \\ Boris Sakakushev ${ }^{1,2}$, Elena Hadzhieva ${ }^{1}$
}

Received: 24 August 2020 / Accepted: 15 September 2020 / Published online: 20 January 2021

(C) The Author(s) 2021. This article is published with open access at https://journal.astes.org.al

\begin{abstract}
Amyand hernia is a rare presentation in inguinal hernias (less than $1 \%$ of cases with inguinal hernias) which is evidenced when in herniated masses the presence of inflamed appendix is ascertained or not. It was named after a French surgeon, Claudius Amyand (1660-1740), who performed the first successful appendectomy in 1735, where he found an acute appendicitis in a herniated mass. Most cases are diagnosed intraoperatively, as an accurate preoperative diagnosis rarely becomes evident.

Management is individual depending on the stage of inflammation of the appendix, the presence of abdominal sepsis and concomitant factors. The decision should be based on factors such as the patient's age, the size and anatomopathological shape of the appendix, and in the case of an inflamed appendix, standard appendectomy and retinal herniorrhage should be the gold standard of treatment.

Amyand hernia is usually misinterpreted as a common incarcerata hernia. Symptoms that mimic appendicitis may appear. Treatment consists of a combination of appendectomy and hernia repair. The inflammatory status of the appendix determines the type of hernia repair and the surgical technique. Occasional appendectomy in the case of a normal appendix is not recommended.

Amyand hernia is a rare type of inguinal hernia in which the appendix is located in the hernia sac. We present a case of a recurrent incarcerated Amyand's hernia with complicated appendicitis. The 78 old polymorbide patient with right-sided incarcerated recurrent hernia was emergently operated on and appendectomy and non-mesh hernioplasty performed, on the $3^{\text {rd }}$ postoperative day for a heart attack he was placed cardio stimulator with uneventful outcome. Fifteen months follow up did not show complications or complaints.

Keywords: Amyand's hernia, complicated appendicitis, hernia incarceration, local peritonitis
\end{abstract}

\section{Introduction}

Amyand hernia is a rare type of inguinal hernia in which the appendix is located in the hernia sac. Claudius Amyand first in 1735 described a case of successful appendectomy in an 11-year-old boy for a perforated appendix with an intestinal fistula in right-sided inguinal hernia [1,2]. Since 1953 in abdominal surgery the term "hernia Amyand" was introduced in honor of the French surgeon, Claudius Amyand (1660-1740), [3]. The disease is extremely rare, varies from 0.13 to $1 \%$ of all inguinal hernia cases, occurs

Original article, no submission or publication in advance or in parallel

\footnotetext{
* Corresponding author: Dimitar HADZHIEV MD

\adzhievd@yahoo.com

1 First Clinic of Surgery, University Hospital "St. George ", Plovdiv BULGARIA,

2 Chair of Propaedeutics of Surgical Diseases, Medical University Plovdiv, BULGARIA
}

mainly in males and is almost exclusively on the right side $[4,5,6]$. Many authors believe that the true incidence of the disease is lower than classically described [7,8].Children and adults suffer more often due to weaker intestinal fixation and demonstrate increased mobility [3,9] Losanoff J. and Basson M. first described a clinical classification with four types in Amyand hernia [10].

The clinical picture of the disease is nonspecific and in almost in all cases the diagnosis is intraoperative. CT, MRI, and inguinal ultrasound can improve preoperative identification of Amyand hernia [6,11]. In the case of incarcerated right inguinal hernia and lack of pathological data for air-fluid levels on abdominal radiography, some authors consider this as a possible indirect sign of the presence of a trapped "Amyand hernia" [12].Different clinical variants are described according to the location of the appendix in the hernia sac: only the tip of the appendix located in the sac, the entire appendix located in the sac and appendicular, the body and tip located in the abdominal cavity. A conducted large-scale systematic search in the medical database found a total of 161 patients with Amyand hernia, and the following types of appendix: normal - 73 
(45.4\%), uncomplicated - $62(38.5 \%)$ and perforated - 26 $(16.1 \%)$ [13].

Issues of importance are time of incarceration to operation and the extent of peritonitis. In all cases of hernia incarceration and appendicitis - both appendectomy and herniotoimy should be performed.

\section{Case presentation}

We present a case of a recurrent incarcerated Amyand hernia with complicated appendicitis. The patient T.G.U. at the age of 78 with hospital ID № 35263 was admitted urgently in the University Hospital "St. George "- Plovdiv, First Clinic of Surgery on June 11, 2015, with clinical data for rightsided incarcerated recurrent hernia.

The present history was of a painful swelling in the right inguinal area with one day duration. Local pain grew stronger, accompanied with nausea, vomiting and febrility. The patient did have complaints for this hernia more than five years. He underwent surgery three years ago for it and had recurrence at the end of the first year.

On admission, the patient's condition was unsatisfactory. Pulse rate was 70 bpm, BP - 100/60 mmHg. Tongue was dry.

The local physical examination revealed an old scar from the previous operation in the right inguinal area and a fixed, painful on palpation swelling of $5 / 7 \mathrm{~cm}$. The invagination digital test was negative. The abdomen was respiratory active, at the chest level, painful in the right inguinal area, without the presence of peritoneal irritation, Blumberg (-) neg., Slightly increased peristalsis was present.

Previous disease history included two brain strokes, a myocardial infarction, AH III, CIHD, RCD, HF II, Triple branch coronary disease, AV block III, mitral valve regurgitation, cerebrovascular disease.

Laboratory tests showed leukocytosis (Wbc) - 14.7 x10 $\wedge 9$ / 1, mild anemia - Rbc-4.21 x10^ 12 / 1, Hb-125.0 g / 1, Hct-0.384 1 / 1. Biochemical tests and coagulogram - n.a.d/ no abnormalities detected/. Abdominal radiography - lack of free gas or air-fluid intestinal levels.

The pre-operative diagnosis, based on clinical and laboratory data was considered as "Recurrent incarcerated inguinal hernia". After a short preoperative preparation, the patient underwent emergency surgery with spinal anesthesia. Oblique (indirect) incarcerated hernia right inguinal hernia was found. After dissection, the hernial sac was opened, from which was evacuated $30 \mathrm{ml}$ dark bloody odorless exudate. A microbiological sample was taken. Gangrenous, incarcerated in the upper third appendicitis was found, with partially incarcerated and fused omentum, with local peritonitis/purulent deposits/, without perforation. Debridement and adhesiolysis was done, revealing and appendix of $10 \times 1.5 \mathrm{~cm}$, covered with purulent deposits. The caecum was presented and the base of the appendix ligated with a single suture and a transfix one of the mesoappendix. Typical appendectomy was performed, covering the stump with purse-string and Z-shaped suture. No effusion was detected intraperitoneally. Local lavage and Halstead hernia repair was done without mesh because of the advanced local tissue infection. Thus the patient underwent Herniotomy, Debridement, Adhesiolysis, Appendectomy, Lavage and Halstead inguinal hernia repair.

On the third postoperative day, the patient suddenly complained from severe retrosternal pain, shortness of breath and collapse. He was consulted with an internist and cardiologist and with acute coronary syndrome was transferred to the Invasive Cardiology Clinic, where a temporary pacemaker (EKS) was placed. SCAG (selective coronary angiography) was conducted, followed by balloon PTCA of RCAp. After the invasive procedure, the patient was strictly monitored, hemodynamically stable and with a marked reduction in subjective complaints. The next day, the temporary one was removed and PEX VVI was implanted. The patient was in satisfactory condition, without complaints and rehabilitated to self-care. After the invasive procedure he was discharged on the third day in good general condition.

The consultation with a surgeon registered primary wound healing, followed by suture removal and discharge. The histological result/B№12068-69/ showed phlegmonous appendicitis with periappendicitis. Microbiological testing/№5613/ of peritoneal culture was (-) negative and no pathogenic microorganisms were isolated.

The two recent post-dischsrge surgical examinations did not register any complaints.. The patient was followed for 15 months, with no abdominal complaints and no evidence of hernial recurrence.

Specific in this clinical case is that the hernial incarceration and the appendicitis are the subject of emergency abdominal surgery. The incarcerated inguinal hernia was diagnosed preoperatively, and destructive appendicitis was diagnosed intraoperatively., The patient underwent surgery for appendicitis and local peritonitis with a traditional parainguinal incision. In case of widespread peritonitis with exudate, herniolaparotomy or rarely lower midline laparotomy is advocated. Laparoscopic inguinohernioplasty can be done safely, using TEP or TAPP $[14,15]$. In case of an unchanged appendix in the hernial sac, there is no standardized operative approach, as the treatment depends on the personal choice of the surgeon $[16,17]$.

\section{Conclusion:}

Complicated appendicitis in Amyand's incarcerated hernia is very rare clinical complication in the field of herniology. Due to difficult verification of complicated appendicitis in the incarcerated inguinal hernia by physical examination, image investigations can help the preoperative diagnosis.

Surgery depends on the elapsed time of the incarceration, the destructive changes in the appendix, the prevalence of peritonitis changes and patient general condition.

COI Statement: This paper has not been submitted in parallel. It has not been presented fully or partially at a 
meeting or podium or congress. It has not been published nor submitted for consideration beforehand.

All authors declare that there is no conflict of interest. This research received no specific grant from any funding agency in the public, commercial, or nonprofit sectors. There are no relevant or minor financial relationships from authors, their relatives or next of kin with external companies.

Disclosure: The authors declared no conflict of interest. No funding was received for this study.

\section{References:}

1. Manzanares-Campillo M., Muñoz-Atienza V., SánchezGarcía S., et al. Amyand's hernia: a report of two cases and review of the bibliography. Cir.Cir., 2014, 82(2), 195-199.

2. Morales-Cardenas A., C.F. Ploneda-Valencia, V.H. SainzEscarrega et al. Amyand hernia: case report and review of the literature. Ann Med Surg., 2015, Vol. 4 (2). - P.113-115.

3. Singal R., Gupta S. «Amyand's hernia» - pathophysiology, role of investigations and treatment. J. Clin. Med., 2011, Vol. 6, № 4. P. 321-327.

4. Nigri G, Costa G, Valabrega S, et all. A rare presentation of Amyand'shernia. Case report and review of the literature. Minerva Chir., 2008; 63(2):169-174.

5. Sharma H., Gupta A., Shekhawat N. S. et al. Amyand's hernia: a report of 18 consecutive patients over a 15 -year period. Hernia, 2007. Vol. 11. P. 31-35.

6. Okur M.H., Karaçay S., Uygun I. et al. Amyand's hernias in childhood (a report on 21 patients): a single-centre experience. Pediatr.Surg.Int., 2013, 29 (6), 571-574.

7. Michalinos A., Moris D.,Vernadakis S.Amyand's hernia: a review. Am. J. Surg., 2014, 207(6), 989-995.
8. Kromka W., Raub A., Fox C. Amyand's hernia with acute gangrenous appendicitis and cecalperforation: A case report and review of the literature. International Journal of Surgery Case Reports, 44, 2018, 8-10.

9. Solecki R., Matyja A., Milanowski W. Amyand's hernia: a report of two cases. Hernia, 2003. Vol. 7. P. 50-51.

10. Losanoff J.E., Basson M.D. Amyand's hernia: a classification to improve management. Hernia, 2008. Vol. 12. P. 325-326.

11. Guler I., Alkan E., Nayman A., Tolu I. Amyand's Hernia: Ultrasonography Findings. J Emerg Med., 2016 Jan, 50(1), p.15-7.

12. Salemis NS, Nisotakis K, Nazos K, Stavrinou P, Tsohataridis E. Perforated appendix and periappendicular abscess within an inguinal hernia. Hernia, 2006, 10 (6) : 528-530.

13. Papaconstantinou D. , Garoufalia Z., Kykalos S et al. Implications of the presence of the vermiform appendix inside an inguinal hernia (Amyand's hernia): a systematic review of the literature. Hernia, 2020 May 25. doi: 10.1007/s10029020-02215-5.

14. Syllaios A, Davakis S, Kyros E. et al. Laparoscopic repair of Amyand's hernia complicated with acute appendicitis. Report of a case. Journal of Surgical Case Reports, 2019;6, 1-3

15. Han S., Li M., Lai H. A total laparoscopic treatment strategy for Amyand's herniacomplicated with appendicitis: A case report. International Journal of Surgery Case Reports, 59, 2019, 11-14.

16. Ivanschuk G., Cesmebasi A., Sorenson E. et al. Amyand's hernia: a review. Med Sci Monit., 2014, Vol.20., P.140-146.

17. Karatas A., O. Makay, Z. Salihoglu. Can preoperative diagnosis affect the choice of treatment in Amyand's hernia? Report of a case. Hernia, 2008, Vol.13, P.225-7. 